\title{
Modeling the contribution of pig farming to pollution of the Thachin River
}

\author{
Monika Schaffner · Hans-Peter Bader • \\ Ruth Scheidegger
}

Received: 15 May 2009/Accepted: 6 August 2009/Published online: 22 August 2009

(C) Springer-Verlag 2009

\begin{abstract}
Rapid growth of the livestock production sector in South-East Asia during recent decades has led to a widespread degradation of ground and surface waters. The Thachin River Basin in Central Thailand serves as a case study for investigating the origins and pathways of nutrient loads produced by intensive pig farming. A mathematical material flow analysis is used to identify key nitrogen flows and the main parameters determining them. Scenarios of the potential for reducing these flows and achieving compliance with current discharge regulations are investigated. The results show that liquid waste discharged from large pig farms and directly discharged waste from small farms are the key nitrogen flows to the river system. The key driving forces are not only the treatment coverage and efficiencies but also the rate of reuse and recycling of the treated product.
\end{abstract}

Keywords Material flow analysis - Nitrogen - River water pollution control $\cdot$ Pig manure management . Thachin River · Thailand

\footnotetext{
M. Schaffner $(\bowtie)$

Institute of Geography, University of Bern, Hallerstrasse 12, 3012 Bern, Switzerland

e-mail: monikaschaffner@bluewin.ch

M. Schaffner · H.-P. Bader · R. Scheidegger

Eawag, Swiss Federal Institute of Aquatic Science and

Technology, Ueberlandstrasse 133, P.O. Box 611, 8600

Duebendorf, Switzerland

e-mail: bader@eawag.ch

R. Scheidegger

e-mail: ruth.scheidegger@eawag.ch
}

\section{Introduction}

Livestock production in Asia has intensified greatly in recent decades (Steinfeld et al. 2006). The rising incomes of a growing population, furnished by a strong economic development, are generating increasing demand for animal products. In Thailand, pig production grew by over $50 \%$ between 1988 and 1998, and this growth is expected to continue (Rattanarajcharkul et al. 2000). It is particularly apparent around urban centers such as in Thailand's central basin (Gerber et al. 2004). Mismanagement of livestock excreta, together with lack of proper treatment provisions and waste reuse, has led to widespread degradation of ground and surface waters (Gerber 2006). Studies on largescale regional nutrient balances in South-East Asia (Badayos and Dorado 2004; Gerber et al. 2004) have shown an imbalance in regional nutrient flows caused by intensive livestock production, underlining the importance of reusing livestock waste as nutrients in crop agriculture.

In the Thachin River Basin (TRB), an intensively developed area in the central plains of Thailand and one of the country's major regions for livestock production (DLD 2004), the degradation of surface water quality has become of great governmental and public concern during recent years (Office of Natural Resources and Environmental Policy and Planning 2002; Simachaya 2003). A water quality crisis in May 2000, associated with a major fish death due to a sudden drop in oxygen levels in the river, was the trigger to introduce river water quality remediation efforts (Simachaya 2003). The crisis is attributed to unseasonal heavy rainfall which caused extensive pollution discharge from non-point sources. Until then, government policies had only covered pollution from point sources. A widely held view, underscored by several estimates of organic and nutrient loading throughout the basin (PCD 
et al. 1997; Simachaya 1999; Simachaya 2003), is that primarily point sources are a problem and that pig farms are among the main pollution sources. This hypothesis is easily believed considering the number of pigs in Nakhon Pathom Province, a major pig production province located in the center of the TRB (DLD and PCD 2002), alone. The pig population was 0.85 million in 2001 (DLD and PCD 2002) — close to one pig per inhabitant. A study by the Pollution Control Department of Thailand (PCD) estimates a daily wastewater discharge of $125 \mathrm{t}$ from pig farms in Nakhon Pathom province, several orders of magnitude greater than that of duck and aquaculture farms, with 10.6 and $1.5 \mathrm{t}$ respectively (PCD 1996, in: Kwanmeung 2002). However, no study has yet explicitly compared the nutrient loads produced at the origins of the various point sources such as households, industries, pig, poultry, and fish farms with diffuse sources such as rice, fieldcrop, fruit, and vegetable production.

The current approach to address river water pollution in the TRB is based on conventional, catchment-based water quality models, such as WASP (Simachaya 1999), QUAL2E (PCD and Pro-En Technologies 2002), and MIKE11 models (PCD and Environmental Consultant 2004). These models estimate the quantity of pollution discharge to the river from the various point- and non-point pollution sources on the basis of per-capita pollution discharge (point sources) and GIS-based land-use-specific runoff estimations (non-point sources). However, the models fail to address the question of the origin of these various pollution loads; and the simulated scenarios for river water quality remediation do not sufficiently specify concrete remediation measures.

Knowledge about the pollution inputs is crucial, in particular for all the river quality models, since their accuracy directly determines the uncertainty of the model results. A regional research project aimed at re-linking livestock waste generation with agricultural production (DLD and FAO 2004) developed a nutrient flow model for livestock production (NuFlux) (Menzi et al. 2002). This excel-based model uses input and output values as well as transfer coefficients to quantify the nutrient flows on a specific pig or poultry farm. To a certain extent, the model allows tracing the origins of nutrient loads from pig and poultry production. However, the calculations are limited to the farm scale and are not designed to compare different waste management options with the aim of reducing nutrient loads to surface water bodies on a basin scale.

In order to gain a solid basis for possible water-quality remediation measures in the TRB, it is necessary to obtain an overview of the pollution flows from their origin, following their flow path to their discharge into the river. The key parameters influencing these flows need to be identified to determine the most effective remediation. The objective of this study is to quantify and model the nutrient flows from pig farms into the Thachin River. The following questions provided the starting point for the research presented here:

- Is pig farming as polluting as it is believed to be?

- What are the key nutrient flows of the system of pig farming to the surface waters in the TRB; and what are the key parameters driving these flows?

- What are the possible measures that could be taken to most effectively reduce nutrient pollution from pig farming?

This study is part of a more comprehensive research project that aimed to quantify the main pollution sources and their contributions to the overall TRB (Schaffner et al. 2005, 2009; Schaffner 2007).

\section{Study area}

The Thachin River is an effluent tributary of the Chao Phraya River, draining the western part of the central plains of Thailand (Fig. 1). It branches off approximately $175 \mathrm{~km}$ to the northwest of Bangkok in Chainat Province, flows through Suphanburi, Nakhon Pathom, and Samut Sakhon provinces to join the Gulf of Thailand around $45 \mathrm{~km}$ west of Bangkok. The $12,000 \mathrm{~km}^{2}$ basin is characterized by intensive land-use: high-yield agriculture, industrialized livestock production and fisheries as well as increasing urbanization and industrialization. Today, the Thachin River has become a focal point of governmental and public concern and has been identified as a priority area for Environmental Action by the Pollution Control Department of Thailand (FAO and DLD 2002).

The TRB is a center of Thailand's pig farming industry, covering roughly $15 \%$ of the country's pork production. The pig population of the basin varies from year to year according to the market price of pork. In 2004, roughly 1 million pigs were raised in 12,650 farms, of which $34 \%$ were located near the main water bodies (DLD 2004). Pig farms are mostly private sector initiatives, $30 \%$ of them of small size with less than 500 pigs and $60 \%$ of them of medium size with 500-5,000 pigs; the remaining farms are large industrialized livestock operations with more than 5,000 pigs (Adisorn, pers. comm.). Pigs are generally held in open housing systems, on slatted floors for breeding sows and piglets, and on solid floors for fatteners (male pigs raised for pork production) (Rattanarajcharkul et al. 2000). Slaughterhouses are separate enterprises located close to the production units. They are still largely traditional family-run enterprises with a capacity ranging from 1-200 pigs to a maximum of 700 pigs per day (Kattaporn, pers. comm.; Gerber 2006).

The coverage and efficiency of wastewater treatment systems in pig farms and slaughterhouses are relatively low. 


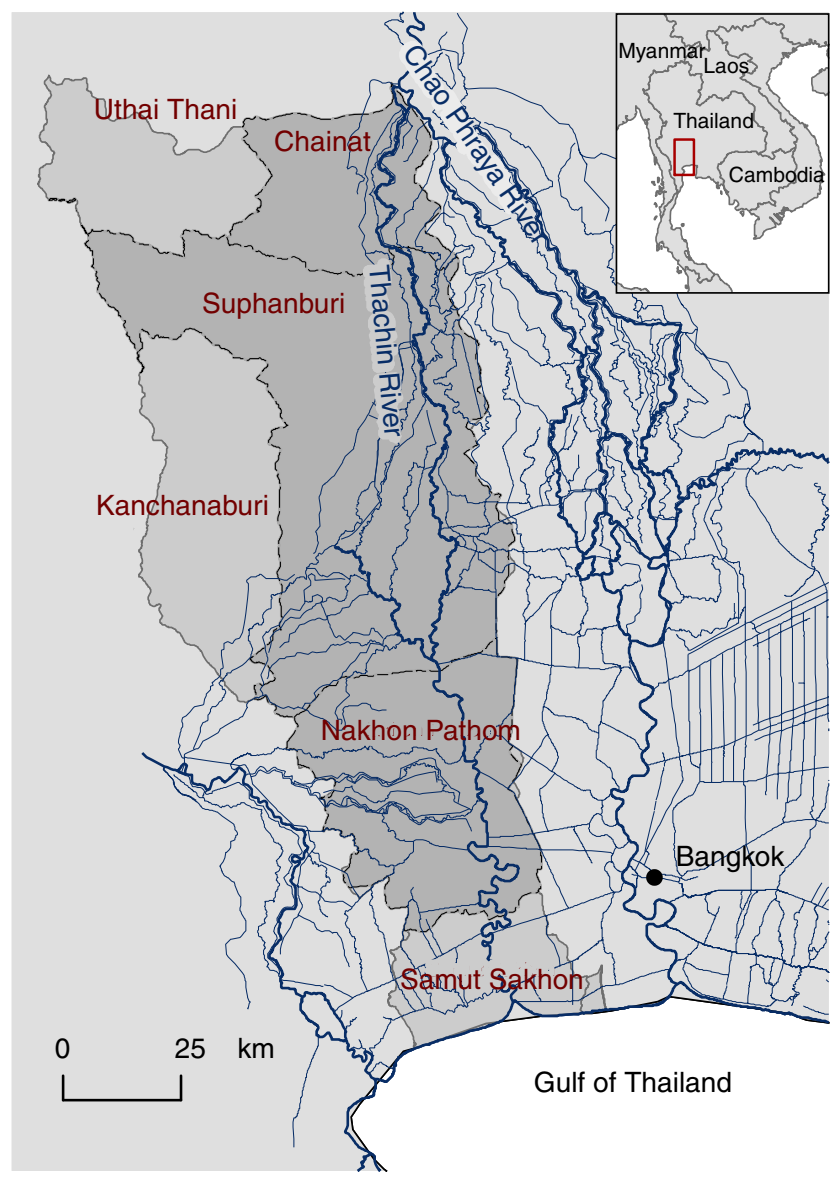

Fig. 1 Thachin River Basin and its main provinces, located in Central Thailand; dark gray $=$ modeled area, light gray $=$ total basin area [GIS sources: PCD (1995), Kasetsart University and IRD (1996)]

Dung is considered a valuable resource (Rattanarajcharkul et al. 2000) and is largely collected separately to fertilize adjacent cropland or fish ponds or to sell within and outside the region. Liquid waste is collected and treated in natural pond systems (earth lagoons) or discharged directly into the nearby canals (Kwanmeung 2002); few farms use more advanced anaerobic digester treatment systems. Reuse of liquid manure is rare due to its low fertilizing value and high handling and transportation costs (DLD and FAO 2004).

\section{Methods}

The method used in this study is a mathematical material flow analysis (MMFA) which is an extension of the traditional material flow analysis (MFA) by modeling concepts.

The MFA was introduced and adapted to regional studies in the 1980s by Brunner et al. (1990) and Baccini and Brunner (1991). The first regional study in the Bünz valley of Switzerland (Brunner et al. 1990) gave an overview of the regional substance flows of $\mathrm{N}, \mathrm{Cl}, \mathrm{P}, \mathrm{Cu}, \mathrm{Zn}, \mathrm{Cd}$, and $\mathrm{Pb}$ and showed its potential as a basis for river basin pollution control. Similar studies were performed on a larger scale in the Danube Basin, Austria (Lampert and Brunner 1999; Sarikaya et al. 1999; Somlyódy et al. 1999; Zessner and Kroiss 1999).

The MFA was extended to MMFA by Baccini and Bader (1996). In the last decade, it has been applied in many different studies in various fields (Bader et al. 2006). The method has been used in developing and emerging countries for several purposes, such as to establish a regional water balance (Binder et al. 1997), to model resource management for agricultural systems in Nicaragua (Pfister et al. 2005), and to simulate the water and nutrient flows (N and $\mathrm{P}$ ) for urban wastewater in Kunming, China (Huang et al. 2007).

An MFA-based model describes and quantifies the material (e.g., water and nutrient) flows through a system. Its application to analyze pig farming allows nutrient flows and their transformations to be traced from their input as feed or water, through waste production, separation, treatment, and finally to their output as reusable fertilizer/manure, or as discharge into receiving waters. The approach attempts to obtain an overview of the system and focuses on the main processes involved in the nutrient pollution generation chain. An MMFA is carried out in six steps:

- System analysis: define temporal and spatial boundaries; identify the balance volumes and flows of the system;

- Model approach: formulate the equations to describe the system in mathematical terms;

- Data acquisition and calibration: collect and calibrate the input data set for the model;

- Simulate the Current state, including Uncertainty;

- Sensitivity analysis;

- Scenario calculation: simulate measures to decrease the most polluting flows.

\section{System analysis}

The geographical area considered for the analysis of this study is the upper-to-mid part of the TRB, including the three provinces of Chainat, Suphanburi, and Nakhon Pathom (Fig. 1, dark gray area). The southern-most province of the basin, Samut Sakhon, is excluded because pig farming is negligible in that area $(0.25 \%$ of total pigs in the basin). The system includes the receiving water bodies (Thachin River and Canals), and all the activities related to pig farming (balance volumes) and their interlinkages (flows). However, soil and groundwater are not included. In order to account for eutrophication as an important aspect of water quality deterioration in the Thachin River, the nutrients of total nitrogen $(\mathrm{N})$ and total phosphorus $(\mathrm{P})$ 


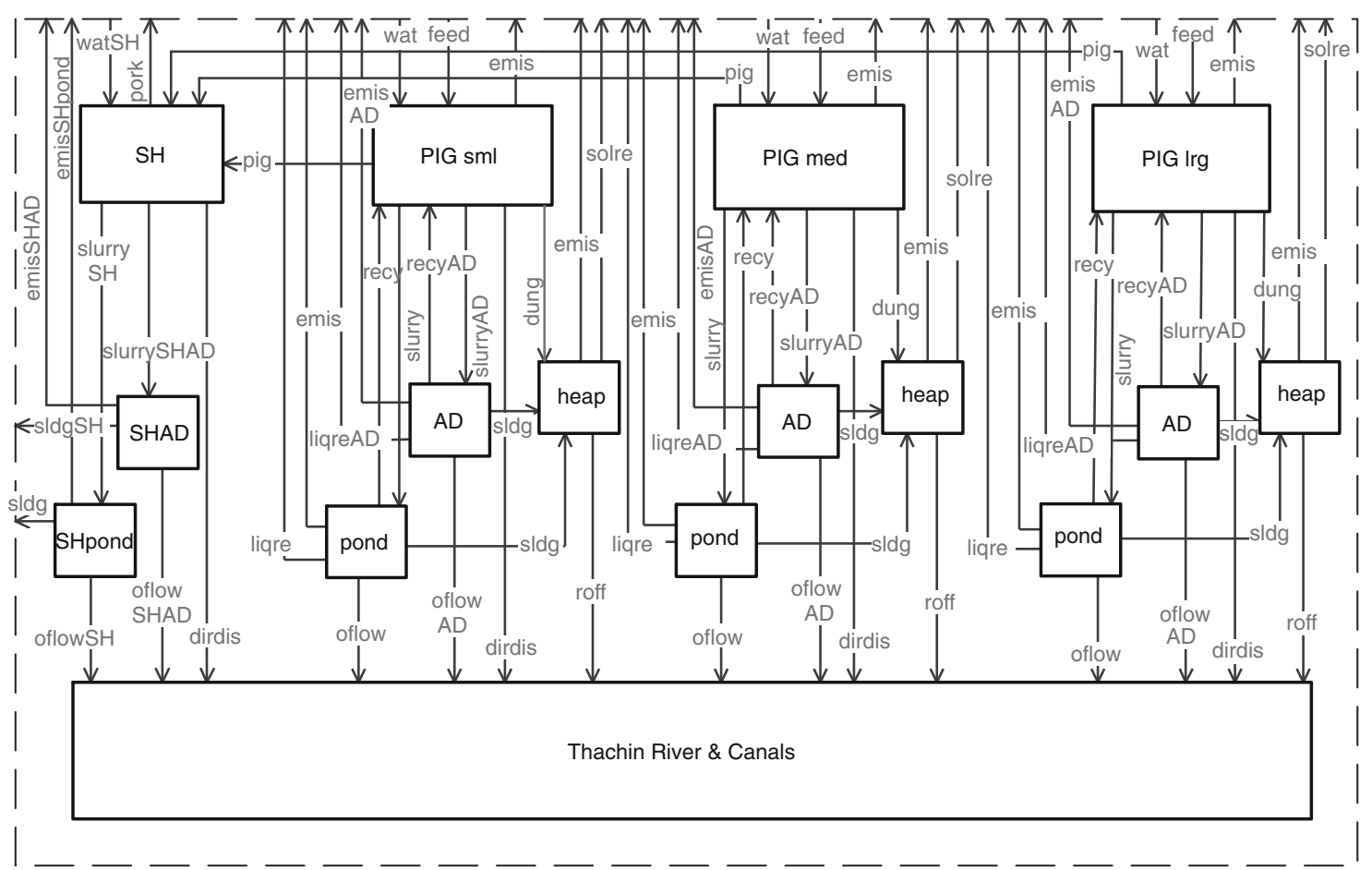

Fig. 2 System analysis for pig farming in the Thachin River Basin (boxes = balance volumes; arrows = mass and nutrient flows; sml small, med medium, lrg large, $S H$ slaughterhouse, $A D$ anaerobic digester)

were chosen as indicators. Water-related mass flows are also quantified, as they are the basis for understanding the nutrient flows. The time scale is 1 year (stationary modeling), simulated for current conditions (year 2006) using the most recent available data. This system is designed for the scale of the overall basin, but can subsequently be downscaled to any smaller spatial unit (e.g., provincial or sub-basin level).

Figure 2 shows the system for pig farming. The boxes represent the balance volumes of the system, and the arrows represent the mass and nutrient flows (inputs, outputs, and interlinking flows). The pig system is composed of three independent pig subsystems linked to the slaughterhouse subsystem $(S H)$. The three pig subsystems represent pig production (PIGsml, PIGmed, PIGlrg) according to the farm size categories of the DLD (small, medium, large) because the farm size generally determines the level of waste treatment technology involved. Table 1 summarizes the abbreviations used in the model.

\section{Model approach}

In order to describe this system, a total of 303 system variables are used: 84 variables per pig farm subsystem model and 51 for the slaughterhouse subsystem model. The variables are interlinked to the other variables and the parameters by equations, on the basis of the acquired system knowledge. The equations describe either demands (such as the water and food demand for pigs) or inputoutput relationships (such as the waste distribution). In mathematical terms, the set of equations is a parameterization (nonlinear) of the relevant flows and stock change rates by a set of 133 parameters. The parameters represent production parameters (such as the number of pig places), operating parameters (such as transfer coefficients), specific physiological parameters (such as the food needed per pig and day) and biological parameters (such as N, P concentrations). The model presented here is a first approximation describing the current system knowledge. The aim was to develop a model which quantifies the $\mathrm{N}$ and $\mathrm{P}$ inputs to the Thachin River from pig farms in a first approximation, rather than to develop a highly detailed process-based model that would be able to describe all the processes very accurately.

The model is implemented in the SIMBOX simulation program (Baccini and Bader 1996). A detailed description of the system analysis and model approach is presented in Schaffner (2007).

Data acquisition and calibration

The input data for the model parameters is drawn from statistics, regional and international research reports, scientific literature, regional monitoring data and expert opinions. These data are combined to produce best estimates for the parameters used. 
Table 1 Abbreviations used in the model

\begin{tabular}{|c|c|}
\hline Abbreviation & Description \\
\hline \multicolumn{2}{|c|}{ Balance volumes (boxes) } \\
\hline SH & Slaughterhouse \\
\hline PIGsml & Small pig farms \\
\hline PIGmed & Medium pig farms \\
\hline PIGlrg & Large pig farms \\
\hline pond & $\begin{array}{l}\text { Liquid waste treatment systems (earth lagoons, waste } \\
\text { stabilization ponds) }\end{array}$ \\
\hline $\mathrm{AD}$ & $\begin{array}{l}\text { Anaerobic digester treatment systems for liquid and/or } \\
\text { solid waste }\end{array}$ \\
\hline heap & Solid waste treatment systems (covered or open heaps) \\
\hline \multicolumn{2}{|c|}{ Mass and nutrient flows (arrows) } \\
\hline pig & Pigs brought to the slaughterhouse for slaughtering \\
\hline pork & $\begin{array}{l}\text { Usable parts of the slaughtered pigs (meat, skin, bones, } \\
\text { etc.) }\end{array}$ \\
\hline wat & Water supply to the pig farms and slaughterhouses \\
\hline feed & Feed supply to the pig farms \\
\hline slurry & $\begin{array}{l}\text { Slurry (mixture of liquid and solid waste) brought to } \\
\text { treatment }\end{array}$ \\
\hline dung & Solid waste brought to the treatment \\
\hline sldg & Sludge resulting from the treatment process \\
\hline recy & $\begin{array}{l}\text { Treated liquid waste recycled in the farm as cleaning/ } \\
\text { cooling water }\end{array}$ \\
\hline liqre & $\begin{array}{l}\text { Treated liquid waste to be reused as fertilizer/irrigation } \\
\text { water in agriculture }\end{array}$ \\
\hline solre & $\begin{array}{l}\text { Treated solid waste to be reused as manure in } \\
\text { agriculture/aquaculture }\end{array}$ \\
\hline oflow & $\begin{array}{l}\text { Overflow/discharge from the treatment system to the } \\
\text { surface water }\end{array}$ \\
\hline roff & $\begin{array}{l}\text { Runoff from the solid waste treatment system to the } \\
\text { surface waters }\end{array}$ \\
\hline dirdis & $\begin{array}{l}\text { Direct discharge of untreated wastewater to the surface } \\
\text { waters }\end{array}$ \\
\hline emis & Water and nitrogen emissions to the atmosphere \\
\hline
\end{tabular}

Regarding pig farming in Thailand, comprehensive data and information is already available. A long-term international research project with a focus on South-East Asia (DLD and FAO 2004) has been studying options to relink intensive livestock with crop production activities to close the regional nutrient cycle. Carried out in the framework of an international initiative on "Livestock, Environment and Development" (LEAD) and coordinated by the Food and Agriculture Organization of the United Nations (FAO), the project aims at developing and testing Area-Wide Integration (AWI) options for specialized livestock production and crop agriculture (Rattanarajcharkul et al. 2000). As one main project activity, a detailed assessment of pig production and waste management systems was carried out in pilot areas in SouthEast Thailand. We consider the studies of South-East
Thailand to be equally representative for the TRB. As this is the pioneer pig-raising area in Thailand, its production and waste management methods were transferred from there to other pig-raising areas (Somchai, pers. comm). A key outcome of the project was an Excel-based decisionmaking tool for enhanced nutrient management in pig farming, NuFlux (Menzi et al. 2002). NuFlux provides a set of standard values (defined in NuFlux as default values) for nutrient-related pig production parameters for Thailand, compiled in collaboration with local experts. This database was used as a starting point for our study, and was complemented by other regional and international literature sources and adjusted to reflect the specific conditions of the TRB. In a final round of expert consultations, the data set was discussed and accepted by the experts. A detailed account of the derivation rationales for the input data is presented in Schaffner (2007).

Tables 2 and 3 show the data set used (average, uncertainty distribution, and source) for our status quo model of small, medium, and large farms, respectively. The three pig farm sub-models differ primarily in their comparative local size (number of pigs) and their treatment coverage and type. Changes apply only for mass parameters, while $\mathrm{N}$ and $\mathrm{P}$ parameters are kept constant for all the farm types due to a lack of more detailed information. Table 4 gives the parameters used for slaughterhouses. Values are indicated in fresh matter (FM), unless otherwise stated.

The uncertainty distributions of each parameter are defined as normal, lognormal or uniform depending on the knowledge of the parameter range and its possible distribution. For fluctuating quantities such as the number of pigs, a normal distribution is assumed. It is known from chemical measurements that quantities such as concentrations and emissions usually have a lognormal distribution. In cases where, according to the current system knowledge, the values are uniformly distributed, such as for transfer coefficients determining manure reuse, a uniform distribution is assumed as a first approximation. In the following text, unless otherwise indicated, the uncertainty was determined on the basis of the assumed accuracy of the data source. Thus $10 \%$ is a high assumed accuracy, 25\% is a moderate assumed accuracy, and $50 \%$ a low assumed accuracy. The average value and standard deviation are indicated as $(\bar{x}, \sigma)$ for normal distributions and as $(\bar{x}, \sigma)$ for lognormal distributions. The range for uniform distributions is indicated as $\left[x_{\operatorname{Min}}-x_{\operatorname{Max}}\right]$.

\section{Results and discussion}

In this article, the simulation results for the MFA model of the pig farming system in the TRB are analyzed and 
Table 2 Data set for the status quo model: parameters used for all the pig farms

\begin{tabular}{|c|c|c|c|c|c|c|c|}
\hline Name & Description & Av. & Distrib. & SD & Min & Max & Source \\
\hline$p_{\text {dw_pig }}$ & Drinking water pigs (1/pig day) & 5 & Lognormal & 2 & & & Nuflux \\
\hline$p_{\text {ccw_pig }}$ & Clean/cool water pigs (1/pig day) & 25 & Uniform & 9.8 & 8 & 42 & $\begin{array}{l}\text { Nuflux; Kwanmeung (2002); } \\
\text { Gerber; Sumet pers. comm. }\end{array}$ \\
\hline$p_{\text {feed_pig }}$ & Feed pigs (kg/pig day) & 2 & Lognormal & 0.5 & & & Nuflux \\
\hline$p_{\text {excr_pig }}$ & Total excreta pigs (kg/pig day) & 5 & Uniform & 2 & 1.5 & 8.5 & See Schaffner (2007) \\
\hline$k_{\text {leach_pond }}$ & Tf leaching pond (out of system) & 0.1 & Lognormal & 0.1 & & & $\begin{array}{l}\text { LDD (1989); Portejoie et al. } \\
\text { (2003); Arux pers. comm. }\end{array}$ \\
\hline$k_{\text {settle }}$ & Tf slurry settle to sludge in pond & 0.2 & Uniform & 0.1 & 0.03 & 0.37 & $\begin{array}{l}\text { Portejoie et al. (2003); Arux } \\
\text { pers. comm.; estimation }\end{array}$ \\
\hline$k_{\text {evp }}$ & Tf net evaporation pond & 0.25 & Uniform & 0.1 & 0.08 & 0.42 & $\begin{array}{l}\text { Thailand Meteorological } \\
\text { Department (2001); estimation }\end{array}$ \\
\hline$k_{\text {biomass }}$ & $\mathrm{Tf}$ biomass in $\mathrm{AD}$ & 0.3 & Uniform & 0.1 & 0.13 & 0.47 & Sommai pers. comm.; estimation \\
\hline$k_{\text {dungsep }}$ & Tf dung separated to heap & 0.55 & Lognormal & 0.35 & & & Nuflux; Burton \\
\hline$k_{\text {roff_heap }}$ & Tf runoff heap to TR & 0.05 & Lognormal & 0.1 & & & $\begin{array}{l}\text { Gerber; Sommai pers. comm.; } \\
\text { estimation }\end{array}$ \\
\hline$k_{\text {dry_heap }}$ & Tf drying/leaching heap (out of system) & 0.5 & Lognormal & 0.15 & & & Nuflux \\
\hline$k_{\text {sol_fish }}$ & Tf heap to fish & 0.45 & Uniform & 0.1 & 0.28 & 0.62 & Adisorn pers. comm. \\
\hline$k_{\text {sol_fcr }}$ & Tf heap to fieldcrops & 0.35 & Uniform & 0.2 & 0.04 & 0.7 & Adisorn pers. comm. \\
\hline$k_{\text {sol_rbed }}$ & Tf heap to fruit and vegetable & 0.2 & Uniform & 0.1 & 0.03 & 0.37 & $\begin{array}{l}\text { Adisorn; Korparditskul pers. } \\
\text { comm.; estimation }\end{array}$ \\
\hline$k_{\text {liq_fcr }}$ & Tf fertigation to fieldcrops & 0.85 & Uniform & 0.06 & 0.75 & 0.95 & Adisorn pers. comm. \\
\hline$k_{\text {liq_fish }}$ & Tf fertigation to fish & 0.1 & Uniform & 0.05 & 0.01 & 0.19 & Adisorn pers. comm. \\
\hline$k_{\text {excav }}$ & Tf sludge excavated from pond & 0.3 & Lognormal & 0.2 & & & Adisorn; Sommai pers. comm. \\
\hline$p_{\mathrm{dw}}^{(\mathrm{N})}$ & $\mathrm{N}$ concentration water supply (mg/l) & 0.5 & Lognormal & 0.4 & & & Sinsupan (2004) \\
\hline$p_{\text {feed_pig }}^{(\mathrm{N})}$ & $\mathrm{N}$ concentration pig feed $(\mathrm{g} / \mathrm{kg})$ & 25 & Lognormal & 7 & & & $\begin{array}{l}\text { Nuflux; Rattanarajcharkul et al. } \\
\text { (2000); Sumet pers. comm. }\end{array}$ \\
\hline$k_{\text {dungsep }}^{(\mathrm{N})}$ & Tf $\mathrm{N}$ separated to dung & 0.4 & Lognormal & 0.2 & & & Nuflux \\
\hline$p_{\text {excr_pig }}^{(\mathrm{N})}$ & $\mathrm{N}$ per capita excreta pig (g/cap day) & 38 & Uniform & 15 & 12 & 64 & See Schaffner (2007) \\
\hline$k_{\text {emis_pig }}^{(\mathrm{N})}$ & Tf $\mathrm{N}$ emission pig house & 0.2 & Lognormal & 0.1 & & & $\begin{array}{l}\text { Nuflux; Van der Peet-Schwering } \\
\text { et al. (1999) }\end{array}$ \\
\hline$k_{\text {emis_heap }}^{(\mathrm{N})}$ & Tf $\mathrm{N}$ emission heap & 0.4 & Lognormal & 0.15 & & & Nuflux \\
\hline$k_{\text {emis_pond }}^{(\mathrm{N})}$ & Tf $\mathrm{N}$ emission pond & 0.25 & Uniform & 0.1 & 0.08 & 0.42 & $\begin{array}{l}\text { Nuflux; Portejoie et al. (2003); } \\
\text { estimation }\end{array}$ \\
\hline$k_{\text {emis_AD }}^{(\mathrm{N})}$ & Tf $\mathrm{N}$ to gas $\mathrm{AD}$ & 0.2 & Lognormal & 0.05 & & & Sommai pers. comm. \\
\hline$k_{\mathrm{settle}}^{(\mathrm{N})}$ & Tf $\mathrm{N}$ settled to sludge in pond & 0.2 & Uniform & 0.1 & 0.03 & 0.37 & $\begin{array}{l}\text { Portejoie et al. (2003); Arux } \\
\text { pers. comm.; estimation }\end{array}$ \\
\hline$k_{\text {biomass }}^{(\mathrm{N})}$ & Tf $\mathrm{N}$ to biomass $\mathrm{AD}$ & 0.3 & Uniform & 0.1 & 0.13 & 0.47 & Sommai pers. comm.; estimation \\
\hline$p_{\mathrm{dw}}^{(\mathrm{P})}$ & $\mathrm{P}$ concentration water supply $(\mathrm{mg} / \mathrm{l})$ & 0.5 & Lognormal & 0.4 & & & Sinsupan (2004) \\
\hline$p_{\text {feed_pig }}^{(\mathrm{P})}$ & $P$ concentration pig feed $(\mathrm{g} / \mathrm{kg})$ & 5.4 & Lognormal & 0.5 & & & $\begin{array}{l}\text { Nuflux; Rattanarajcharkul et al. } \\
\text { (2000); Sumet pers. comm. }\end{array}$ \\
\hline$k_{\text {dungsep }}^{(\mathrm{P})}$ & Tf $\mathrm{P}$ separated to dung & 0.6 & Lognormal & 0.1 & & & Nuflux \\
\hline$p_{\text {excr_pig }}^{(\mathrm{P})}$ & P per capita excreta pig (g/cap day) & 8 & Uniform & 4 & 1 & 15 & See Schaffner (2007) \\
\hline$k_{\text {roff_heap }}^{(\mathrm{P})}$ & Tf $\mathrm{P}$ runoff heap & 0.2 & Uniform & 0.1 & 0.03 & 0.37 & Estimation \\
\hline$k_{\text {settle }}^{(\mathrm{P})}$ & Tf $\mathrm{P}$ settled to sludge in pond & 0.45 & Lognormal & 0.05 & & & $\begin{array}{l}\text { Portejoie et al. (2003); Arux } \\
\text { pers. comm.; estimation }\end{array}$ \\
\hline$k_{\text {biomass }}^{(\mathrm{P})}$ & Tf $\mathrm{P}$ to biomass $\mathrm{AD}$ & 0.45 & Lognormal & 0.05 & & & Sommai pers. comm.; estimation \\
\hline
\end{tabular}

Tf transfer coefficient

Average value (av.) and uncertainty distribution (distrib.: standard deviation or minimum and maximum values) 
Table 3 Data set for the status quo model: specific parameters used for the various farm types

\begin{tabular}{|c|c|c|c|c|c|c|c|}
\hline Name & Description & Av. & Distrib. & SD & Min & $\operatorname{Max}$ & Source \\
\hline \multicolumn{8}{|l|}{ PIGS small } \\
\hline$p_{\text {pigs }}$ & $\begin{array}{l}\text { Pig places small farms } \\
\text { (places/day) }\end{array}$ & 180,000 & Lognormal & 50,000 & & & $\begin{array}{l}\text { DLD and PCD (2002); DLD } \\
\text { (2004); Sumet pers. comm. }\end{array}$ \\
\hline$k_{\text {pond_pig }}$ & Tf slurry pigs to pond & 0.25 & Lognormal & 0.05 & & & $\begin{array}{l}\text { Kwanmeung (2002); Somchai, } \\
\text { pers. comm. }\end{array}$ \\
\hline$k_{\text {ad_pig }}$ & Tf slurry pigs to $\mathrm{AD}$ & 0.07 & Lognormal & 0.02 & & & $\begin{array}{l}\text { Kwanmeung (2002); Somchai, } \\
\text { pers. comm. }\end{array}$ \\
\hline$k_{\text {sepfarm }}$ & $\begin{array}{l}\text { Tf farms separating dung to } \\
\text { heap }\end{array}$ & 0.5 & Uniform & 0.1 & 0.33 & 0.67 & $\begin{array}{l}\text { Arux; Menzi; Somchai; Sumet } \\
\text { pers. comm. }\end{array}$ \\
\hline$k_{\text {fertig_pond }}$ & Tf pond reuse for fertigation & 0.01 & Lognormal & 0.02 & & & Gerber; Sommai, pers. comm. \\
\hline$k_{\text {fertig_AD }}$ & $\mathrm{TF}$ AD reuse for fertigation & 0.01 & Lognormal & 0.02 & & & Gerber; Sommai, pers. comm. \\
\hline$k_{\text {recy_pond }}$ & $\begin{array}{l}\text { Tf pond recycling to pig } \\
\text { house }\end{array}$ & 0.005 & Uniform & 0.002 & 0 & 0.01 & Sommai pers. comm.; estimation \\
\hline$k_{\text {recy_AD }}$ & $\mathrm{Tf} \mathrm{AD}$ recycling to pig house & 0.005 & Uniform & 0.002 & 0 & 0.01 & Sommai pers. comm.; estimation \\
\hline \multicolumn{8}{|l|}{ PIGS medium } \\
\hline$p_{\text {pigs }}$ & $\begin{array}{l}\text { Pig places medium farms } \\
\text { (places/day) }\end{array}$ & 120,000 & Lognormal & 40,000 & & & $\begin{array}{l}\text { DLD and PCD (2002); DLD } \\
\text { (2004); Sumet pers. comm. }\end{array}$ \\
\hline$k_{\text {pond_pig }}$ & Tf slurry pigs to pond & 0.75 & Lognormal & 0.1 & & & $\begin{array}{l}\text { Kwanmeung (2002); Sommai } \\
\text { pers. comm. }\end{array}$ \\
\hline$k_{\mathrm{AD} \_ \text {pig }}$ & Tf slurry pigs to $\mathrm{AD}$ & 0.04 & Lognormal & 0.02 & & & $\begin{array}{l}\text { Kwanmeung (2002); Sommai } \\
\text { pers. comm. }\end{array}$ \\
\hline$k_{\text {sepfarm }}$ & $\begin{array}{l}\text { Tf farms separating dung to } \\
\text { heap }\end{array}$ & 0.8 & Uniform & 0.1 & 0.63 & 0.97 & $\begin{array}{l}\text { Arux; Menzi; Somchai; Sumet } \\
\text { pers. comm. }\end{array}$ \\
\hline$k_{\text {fertig_pond }}$ & Tf pond reuse for fertigation & 0.07 & Uniform & 0.03 & 0.02 & 0.12 & Gerber; Sommai, pers. comm. \\
\hline$k_{\text {fertig_AD }}$ & $\mathrm{TF}$ AD reuse for fertigation & 0.07 & Uniform & 0.03 & 0.02 & 0.12 & Gerber; Sommai, pers. comm. \\
\hline$k_{\text {recy_pond }}$ & $\begin{array}{l}\text { Tf pond recycling to pig } \\
\text { house }\end{array}$ & 0.07 & Uniform & 0.03 & 0.02 & 0.12 & Sommai pers. comm.; estimation \\
\hline$k_{\text {recy_AD }}$ & $\mathrm{Tf} \mathrm{AD}$ recycling to pig house & 0.07 & Uniform & 0.03 & 0.02 & 0.12 & Sommai pers. comm.; estimation \\
\hline \multicolumn{8}{|l|}{ PIGS large } \\
\hline$p_{\text {pigs }}$ & $\begin{array}{l}\text { Pig places large farms } \\
\text { (places/day) }\end{array}$ & 450,000 & Lognormal & 150,000 & & & $\begin{array}{l}\text { DLD and PCD (2002); DLD } \\
\text { (2004); Sumet pers. comm. }\end{array}$ \\
\hline$k_{\text {pond_pig }}$ & Tf slurry pigs to pond & 0.7 & Lognormal & 0.1 & & & $\begin{array}{l}\text { Kwanmeung (2002); Sommai } \\
\text { pers. comm. }\end{array}$ \\
\hline$k_{\mathrm{AD} \_\mathrm{pig}}$ & $\mathrm{Tf}$ slurry pigs to $\mathrm{AD}$ & 0.3 & Lognormal & 0.1 & & & $\begin{array}{l}\text { Kwanmeung (2002); Sommai } \\
\text { pers. comm. }\end{array}$ \\
\hline$k_{\text {sepfarm }}$ & $\begin{array}{l}\text { Tf farms separated dung to } \\
\text { heap }\end{array}$ & 0.85 & Lognormal & 0.1 & & & $\begin{array}{l}\text { Arux, Menzi, Somchai, Sumet } \\
\text { pers. comm. }\end{array}$ \\
\hline$k_{\text {fertig_pond }}$ & Tf pond reuse for fertigation & 0.07 & Uniform & 0.03 & 0.02 & 0.12 & Gerber; Sommai, pers. comm. \\
\hline$k_{\text {fertig_AD }}$ & $\mathrm{TF}$ AD reuse for fertigation & 0.07 & Uniform & 0.03 & 0.02 & 0.12 & Gerber; Sommai, pers. comm. \\
\hline$k_{\text {recy_pond }}$ & $\begin{array}{l}\text { Tf pond recycling to pig } \\
\text { house }\end{array}$ & 0.07 & Uniform & 0.03 & 0.02 & 0.12 & Sommai pers. comm.; estimation \\
\hline$k_{\text {recy_AD }}$ & $\mathrm{Tf} \mathrm{AD}$ recycling to pig house & 0.07 & Uniform & 0.03 & 0.02 & 0.12 & Sommai pers. comm.; estimation \\
\hline
\end{tabular}

Tf transfer coefficient

Average value (av.) and uncertainty distribution (distrib.: standard deviation or minimum and maximum values)

discussed for nitrogen only. Nitrogen serves as a representative example for nutrient pollution, and furthermore, the simulated nitrogen results can be evaluated for compliance with the official water quality standards, which are only defined for nitrogen, and not for phosphorus. The simulation results for phosphorus and waterrelated mass flows are presented in detail by Schaffner (2007). 
Table 4 Data set for the status quo model: parameters for slaughterhouses

\begin{tabular}{llllllll}
\hline Name & Description & Av. & Distrib. & SD & Min & Max & Source \\
\hline \multicolumn{2}{l}{ Slaughterhouse } & & & & & \\
$p_{\text {shw }}$ & Water use SH (1/pig) & 500 & Uniform & 200 & 154 & 846 & Mittal (2006); Kattaporn pers. comm. \\
$k_{\text {fattener }}$ & Fatteners per pig place & 0.75 & Lognormal & 0.15 & & DLD and PCD (2002) \\
$p_{\text {batch }}$ & Fattener batches per year & 2 & Lognormal & 0.3 & & Nuflux; Arux, Kattaporn pers. comm. \\
$k_{\text {pork }}$ & Tf slaughtered pigs to pork & 0.95 & Lognormal & 0.03 & & Sinsupan (2004); Kattaporn; \\
& & & & & & Lamberts pers. comm. \\
$p_{\text {bw_pig }}$ & Weight slaughtered pig [kg/pig] & 90 & Lognormal & 20 & & Nuflux; Kattaporn pers. comm. \\
$k_{\text {pond_sh }}$ & Tf SH wastewater to pond & 0.2 & Uniform & 0.1 & 0.03 & 0.37 & Sommai; Sumet pers. comm. \\
$k_{\text {AD_sh }}$ & Tf SH wastewater to AD & 0.025 & Lognormal & 0.05 & & & Sommai; Sumet pers. comm. \\
$k_{\text {liqre_pond }}$ & Tf SH pond reuse (to fieldcrops) & 0 & Uniform & 0 & 0 & 0 & Sommai pers. comm. \\
$k_{\text {liqre_AD }}$ & Tf SH AD reuse (to fieldcrops) & 0 & Uniform & 0 & 0 & 0 & Sommai pers. comm. \\
$p_{\text {pork }}^{(\mathrm{N})}$ & N concentration pork $(\mathrm{g} / \mathrm{kg})$ & 23 & Normal & 2 & & Nuflux \\
$p_{\text {pork }}^{(\mathrm{P})}$ & P concentration pork $(\mathrm{g} / \mathrm{kg})$ & 5.3 & Normal & 0.3 & & Nuflux
\end{tabular}

Tf transfer coefficient

Average value (av.) and uncertainty distribution (distrib.: standard deviation or minimum and maximum values)

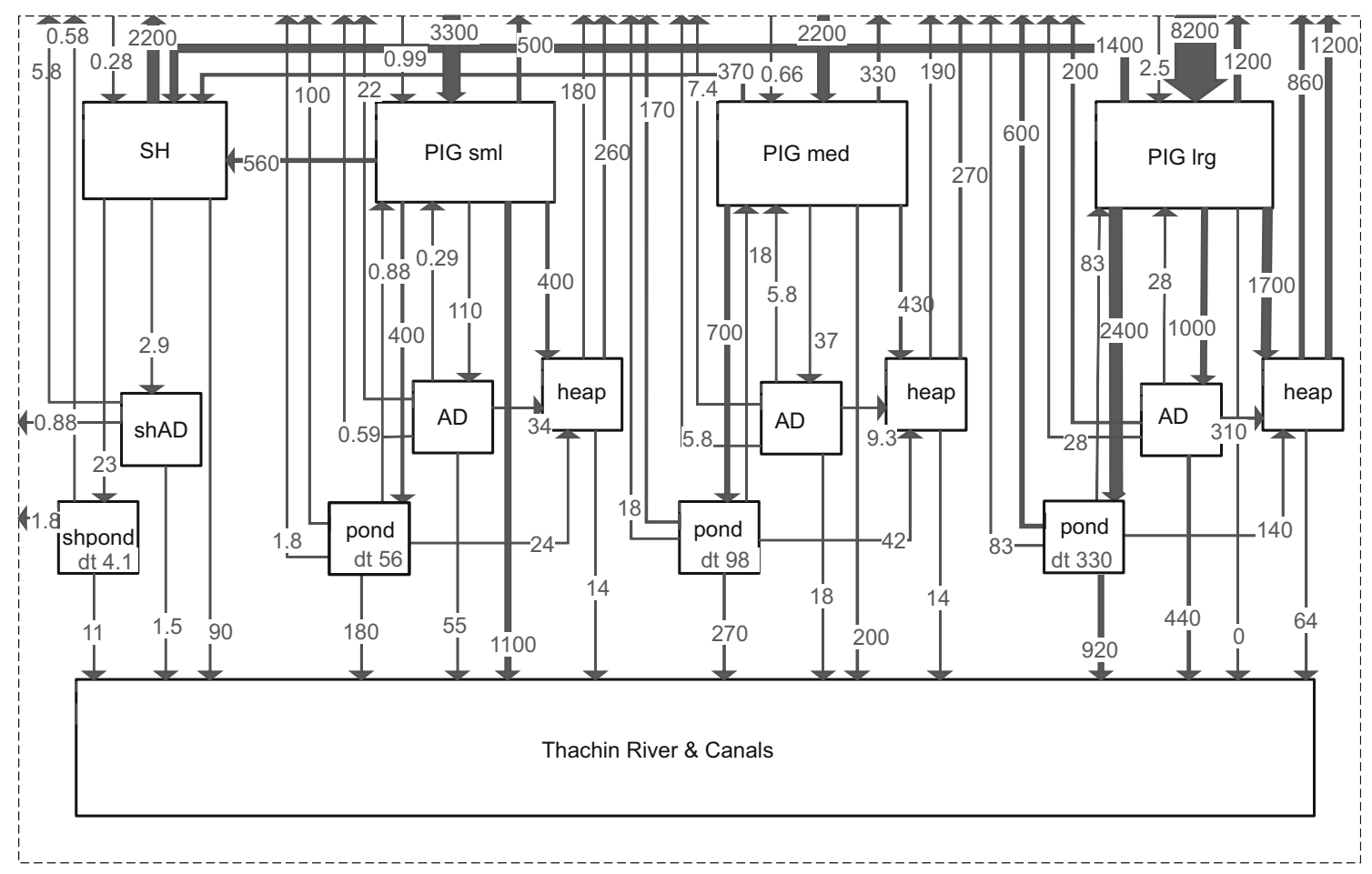

Fig. 3 Simulation results for the status quo of nitrogen flows in the pig farming system of TRB (t N/year) ( $\mathrm{sml}$ small, $m e d$ medium, $l \mathrm{rg}$ large, $S H$ slaughterhouse, $A D$ anaerobic digester, $d t$ stock change rate)

Status quo of nitrogen flows in the pig farming system in the Thachin Basin

\section{Nitrogen loads}

Figure 3 illustrates the simulation results for the status quo of nitrogen flows in the pig farming system of the TRB (the abbreviations are explained in Table 1).
According to the figure, the most significant nitrogen discharge flows to the Thachin River system are the smallfarm direct discharge $(1,100 \mathrm{t} \mathrm{N} / \mathrm{year})$ followed by the POND overflow from large-farms (920 t N/year). Both contribute roughly $30 \%$ to the total pig production-related nitrogen discharge. They are followed by large-farm AD effluent (440 t N/year), which contributes close to $15 \%$. Together, these three flows alone make up more than $70 \%$ 
Table 5 Simulation results for the status quo of nitrogen flows from pig farming systems in Thachin River Basin

\begin{tabular}{|c|c|c|c|c|c|c|c|c|c|}
\hline \multirow{3}{*}{$\begin{array}{l}\text { Flow } \\
\text { Pig places }{ }^{\mathrm{a}}\end{array}$} & \multicolumn{2}{|c|}{ Small farms } & \multicolumn{2}{|c|}{ Medium farms } & \multicolumn{2}{|c|}{ Large farms } & \multicolumn{2}{|c|}{ Slaughterhouse } & \multirow{3}{*}{$\begin{array}{l}\text { Total } \\
\text { basin } \\
750,000 \\
\text { (t N/year) }\end{array}$} \\
\hline & \multicolumn{2}{|l|}{180,000} & \multicolumn{2}{|l|}{120,000} & \multicolumn{2}{|l|}{450,000} & \multicolumn{2}{|l|}{$1,125,000$} & \\
\hline & (t N/year) & $\begin{array}{l}\% \text { Total } \\
\text { basin }\end{array}$ & (t N/year) & $\begin{array}{l}\% \text { Total } \\
\text { basin }\end{array}$ & (t N/year) & $\begin{array}{l}\% \text { Total } \\
\text { basin }\end{array}$ & (t N/year) & $\begin{array}{l}\% \text { Total } \\
\text { basin }\end{array}$ & \\
\hline $\begin{array}{l}\text { Liquid waste produced } \\
\text { (slurry and direct discharge) }\end{array}$ & 1,600 & 26 & 929 & 15 & 3,410 & 56 & 117 & 2 & 6,100 \\
\hline $\begin{array}{l}\text { Solid waste produced } \\
\text { (separated dung) }\end{array}$ & 399 & 16 & 426 & 17 & 1,700 & 67 & - & - & 2,500 \\
\hline Liquid waste discharged & 1,320 & 40 & 483 & 15 & 1,360 & 42 & 102 & 3 & 3,300 \\
\hline $\begin{array}{l}\text { Solid waste discharged } \\
\text { (runoff HEAP) }\end{array}$ & 14 & 15 & 14 & 15 & 64 & 70 & - & - & 90 \\
\hline Total NET discharge to TR & 1,334 & 40 & 497 & 15 & 1,424 & 42 & 102 & 3 & 3,400 \\
\hline $\begin{array}{l}\text { Specific discharge per pig } \\
\text { place }^{\text {b }}(\mathrm{kg} \text { N/year) }\end{array}$ & 7.4 & & 4.1 & & 3.2 & & 0.1 & & 4 \\
\hline Treatment efficiency $\eta^{(\mathrm{N})}$ & 0.33 & & 0.63 & & 0.72 & & 0.13 & & 0.6 \\
\hline
\end{tabular}

${ }^{\mathrm{a}}$ For SH: Slaughtered pigs per year

b For SH: Per slaughtered pig

of the total nitrogen waste discharge to the Thachin River from pig farming.

Table 5 summarizes the nitrogen loads in various waste flows per farm size as well as the specific discharge per pig place and year. These specific discharges are important for the discussion of possible measures to reduce the loads. According to the table, large and small farms contribute a similar proportion of total $\mathrm{N}$ discharge (roughly $40 \%$ ). Medium farms contribute relatively little (15\%), and slaughterhouse discharge accounts for a minimal amount of $3 \%$.

The specific discharge per pig place and year decreases with increasing farm size. This reflects the increase of treatment coverage with increasing farm size.

A comparison of pig waste production (raw solid and liquid waste) and discharge allows the overall nitrogen removal in the different farm types to be estimated (treatment efficiency). This $N$-treatment efficiency is defined as follows:

$\eta^{(\mathrm{N})}=\frac{\text { Total } \mathrm{N} \text { waste produced }- \text { Total } \mathrm{N} \text { discharged to } \mathrm{TR}}{\text { Total } \mathrm{N} \text { waste produced }}$

Table 5 also shows the N-treatment efficiency for the three farm types and the slaughterhouse. Corresponding to the decrease of specific $\mathrm{N}$ discharge, the treatment efficiency increases from small farms to large farms. Slaughterhouses produce a low specific discharge (only a small proportion of the slaughtered pigs is discharged as waste, see parameter $k_{\text {pork }}$ in Table 4), but their $\mathrm{N}$-treatment efficiency is also low.
In order to conclude, key aspects related to the $\mathrm{N}$ loads from pig farming systems of the TRB are as follows:

- The key variables related to nitrogen loads in the Thachin River from the pig farming systems are the effluent/overflow from the liquid manure treatment (POND and AD) of large farms, and directly discharged raw waste from small farms.

- Liquid waste plays the major role in nitrogen discharge to TR from pig farming: over $95 \%$ of total $\mathrm{N}$ is discharged to TR in liquid form, while recycling and reuse rates are minimal. On the other hand, solid pig manure is efficiently reused, and its final contribution to the Thachin River is insignificant, with $3 \%$ of total discharge.

- Small farms contribute almost as much as large farms even though their total number of pigs is 2.5 times lower. This is because the smaller number of pigs is compensated by a higher specific discharge.

- The contribution of slaughterhouses to the total nitrogen load is insignificant compared to pig production. It occurs mainly as untreated direct discharge.

- Nitrogen emissions to air from pig housing and waste management systems are significant flows, representing as much as half of the total excreted N. This high nitrogen loss may be advantageous from a short-term water quality point of view (decreased $\mathrm{N}$ discharge to water), but not from the point of view of greenhouse gas emissions and air pollution (Steinfeld et al. 2006). In the long term, $\mathrm{N}$ emissions to air do not really remove $\mathrm{N}$ from the system because much of the emitted 
$\mathrm{N}$ will return to the area in some form (e.g., as $\mathrm{N}$ deposition by rain).

- According to Jönsson and Vinneras (2003), the specific nutrient excretion of human beings is roughly $11 \mathrm{~g}$ of nitrogen per person and day. In comparison, the specific nitrogen discharge from pig farming to the TRB is in the same range, with an average of $13 \mathrm{~g} / \mathrm{pig}$ day (ranging between $8.7 \mathrm{~g}$ from large farms and $20 \mathrm{~g}$ from small farms).

\section{Uncertainty analysis}

Two different methods for the calculation of the uncertainty were applied:

- Gaussian error propagation: the standard deviation of the variables is calculated using the Gaussian error propagation formula (first-order error propagation).

- Monte Carlo simulation: the probability density distribution of each parameter is described by a sample size of 100,000 each. The corresponding probability density distribution of the variables is then derived by calculating the variable values for each parameter sample. The probability density distribution of each parameter (see Tables 2, 3, 4) was estimated on the basis of the range of values found in various literature sources and expert opinions, and complemented by plausible reasoning.

Our prime interest is the water quality of the Thachin River and its canals. Two aspects are important in this context:

- The nutrient loads to the Thachin River and canals, and

- The nutrient concentrations in the discharge flows to the river and canals.

Concentrations are important because they can be measured and must comply with the regulations. They are discussed below. The loads are important for the environmental impact and, in particular, to determine efficient ways of water quality remediation. It is important to keep in mind that concentrations can easily be decreased by diluting the outflows, whereas the overall nutrient loads would remain the same.

The results for the probability density distribution of the total nitrogen discharge to TR (status quo results) are given in Fig. 4. The probability density distribution of the $\mathrm{N}$ discharge flow has a lognormal shape. A detailed analysis shows that the $\mathrm{N}$ discharge from the total pig system is lower than 2,000 t/year or higher than 5,300 t/year with a probability of only $10 \%$ each. Figure 4 clearly shows the difference between first-order error propagation and Monte Carlo calculation: For small loads, the probabilities differ

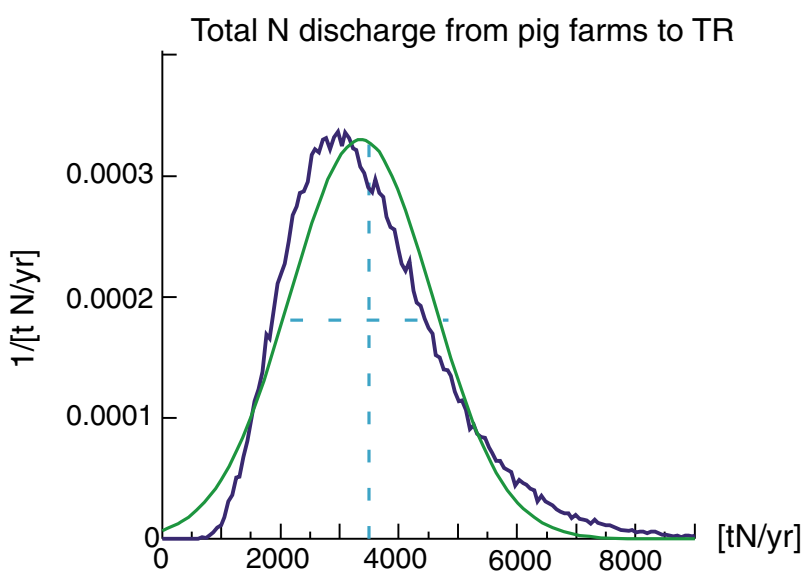

Fig. 4 Probability distribution for the Monte Carlo simulation (black) and Gaussian Error Propagation (gray) for the total nitrogen flow to TR from all the pig farms (t N/year); the area under the curve is equal to 1

strongly between the two approaches. In particular, in contrast to the first-order approximation, the Monte Carlo calculation shows that the discharge is always above $1,000 \mathrm{t}$ N/year.

\section{Nitrogen concentrations}

Table 6 presents the concentrations for all the nitrogen flows discharging to TR from pig farms and slaughterhouses, derived from the model results.

By far the highest nitrogen concentrations are observed in the runoff from the solid manure storage (HEAP). This is the raw runoff concentration, and thus an overestimate, as we do not account for any dilution by the transporting water (rainwater) which would obviously take place during runoff.

Among the liquid discharge flows, the direct discharge and POND overflow have the highest concentrations. This is evident for direct discharge flows, as these are made up of the directly discharged, highly concentrated raw wastewater. The high concentrations of the overflow from the POND systems could be due to the high evaporation rates from the ponds and the resulting increase of concentration in the remaining stored liquids.

A comparison of the discharge concentrations of the three farm types shows a clear decrease of concentration from the small to the large farms, in all the flows. Because the treatment efficiency was set to identical levels for all the farm types in our status quo assumptions (see Tables 2, 3 , parameters $k_{\text {leach_pond }}, k_{\text {settle }}, k_{\text {evp }}, k_{\text {biomass }}, k_{\text {emis_heap }}^{(\mathrm{N})}$, $\left.k_{\text {emis_pond }}^{(\mathrm{N})}, k_{\text {emis_AD }}^{(\mathrm{N})}, k_{\text {settle }}^{(\mathrm{N})}, k_{\text {biomass }}^{(\mathrm{N})}\right)$, this difference must be related with the level of waste management, especially dung separation, which improves with increasing farm size. 
Table 6 Loads, concentrations, and effluent standards for nitrogen flows from pig farming systems and slaughterhouses

\begin{tabular}{|c|c|c|c|c|c|c|}
\hline & Overflow POND & Effluent AD & Direct discharge & Runoff HEAP & Total discharge & Standard $^{\mathrm{a}}$ TKN (mg N/l) \\
\hline \multicolumn{7}{|l|}{ Small farms } \\
\hline Load N (t N/year) & 177 & 55 & 1,088 & 14 & 1,334 & \\
\hline Concentration N (mg N/l) & 850 & 610 & 850 & 3,500 & 840 & None \\
\hline \multicolumn{7}{|l|}{ Medium farms } \\
\hline Load N (t N/year) & 270 & 18 & 195 & 14 & 497 & \\
\hline Concentration N (mg N/l) & 740 & 580 & 740 & 3,400 & 750 & 200 \\
\hline \multicolumn{7}{|l|}{ Large farms } \\
\hline Load N (t N/year) & 923 & 440 & - & 64 & 1,427 & \\
\hline Concentration N (mg N/l) & 720 & 520 & & 2,600 & 660 & 120 \\
\hline \multicolumn{7}{|l|}{ Slaughter-houses } \\
\hline Load N (t N/year) & 11 & 1.5 & 90 & - & 103 & \\
\hline Concentration N (mg N/l) & 210 & 150 & 210 & - & 200 & 100 \\
\hline
\end{tabular}

${ }^{a}$ Thai effluent standards for pig farms (MOSTE 2001) and SH (MOSTE 1996)

Slaughterhouse discharge has a surprisingly low nitrogen concentration, in fact, of an order of magnitude lower than any of the farm effluents. Owing to the large amounts of water used for cleaning purposes together with the low specific waste produced per slaughtered pig (see Table 5); SH wastewater is rather diluted.

The Thai government established effluent standards for medium and large pig farms (MOSTE 2001) as well as for slaughterhouses (MOSTE 1996). These regulations cover nitrogen and organic indicators, but exclude phosphorus. They allow a maximum of $120-200 \mathrm{mg} / \mathrm{l}$ Total Kjeldahl Nitrogen (TKN) for large and medium farms, respectively, and $100 \mathrm{mg} / \mathrm{l} \mathrm{TKN}$ for slaughterhouses (classified as Type 1 factories).

We compare our results with these standards, keeping in mind that TKN only includes organic nitrogen and ammonia, but not nitrate and nitrite, and that, therefore, these standards cannot be directly compared with our simulation results which are based on total nitrogen (organic as well as inorganic). According to our simulation results for the status quo, none of the nitrogen discharge flows complies with the required standards, exceeding these by a factor of between 1.5 and 4 (Table 6).

The uncertainty analysis for the $\mathrm{N}$ concentrations of all the discharge flows is presented in Fig. 5. The probability distributions also have a relatively wide lognormal shape. A detailed analysis shows that the probability for the simulated concentrations to be below the standards is very low: for medium farms: $9 \%$ (POND), $10 \%$ (AD), and 5\% (direct discharge); for large farms: 4\% (POND), 4\% (AD), and $12 \%$ (direct discharge); for SH: $27 \%$ (POND), $35 \%$ (AD), and $22 \%$ (direct discharge). It should be pointed out that the simulations shown here are for average farm types. They cannot be applied to an individual farm.
Spatial disaggregation: downscaling the model to provincial level

In order to investigate the spatial distribution of nitrogen discharges from pig systems, we apply the MFA model on a provincial scale for the three provinces of Chainat, Suphanburi, and Nakhon Pathom. This is done by adapting the parameter $p_{\text {pigs }}$ (pig places; see Tables 2,3 ) according to the provincial numbers (DLD 2004), assuming that all other parameters remain the same as for the overall basin.

Table 7 shows the total nitrogen discharge flows per province and farm type, and their respective importance (\%) in the province and the total basin.

The results of the province-level calculations show that Nakhon Pathom province contributes roughly $70 \%$ of the total pig nitrogen discharge of the basin due to the fact that it is the basin's key pig production area (with roughly $80 \%$ of the basin's pig places). In comparison, Chainat province contributes only with $7 \%$ to the pig-related nitrogen load. The significance of the individual farm types changes from province to province. While small farms dominate in Chainat and Suphanburi provinces, in Nakhon Pathom province, the main contribution comes from large farms. This indicates an important aspect regarding the formulation of water quality remediation policies: the priorities of the targeted farm types should be adapted according to their respective importance in each province.

\section{Plausibility considerations (validation)}

Data on pig farming production and wastewater treatment as well as surface water quality measurements obtained from the international literature and local surveys allow cross checking our modeled results (Table 8). 

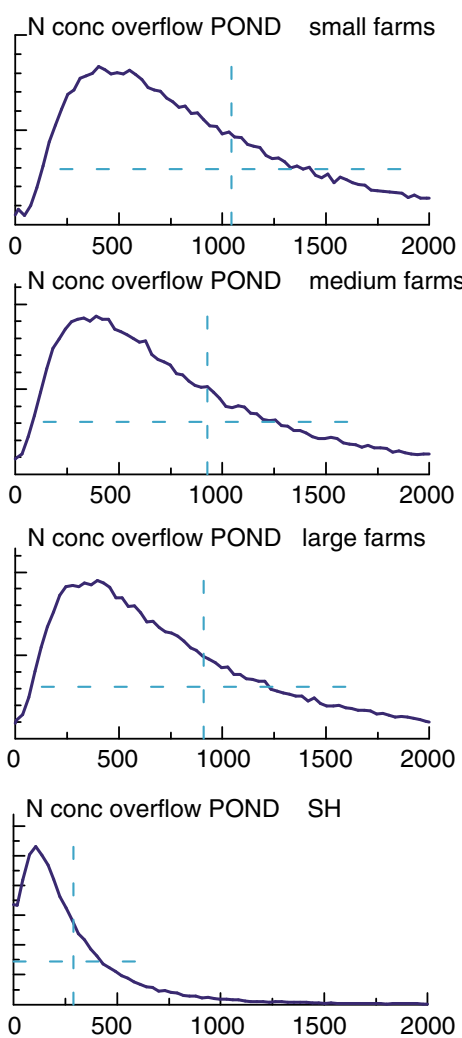
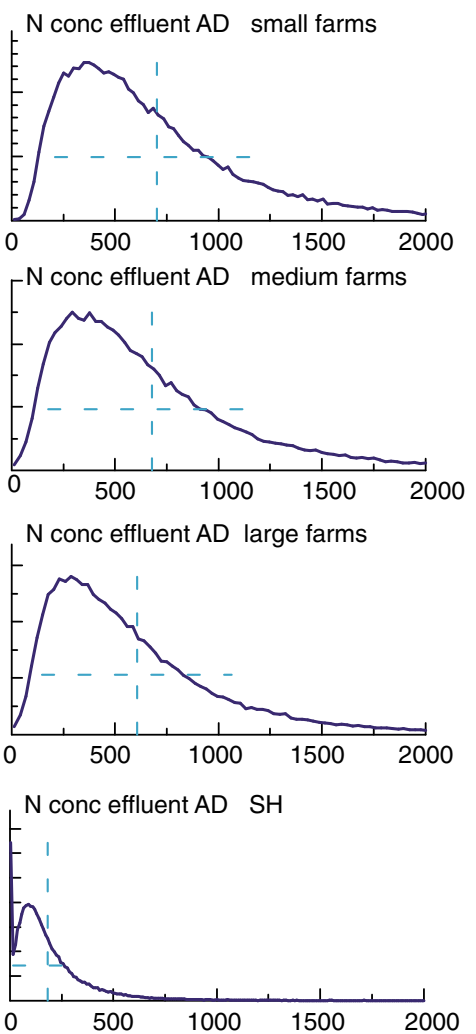
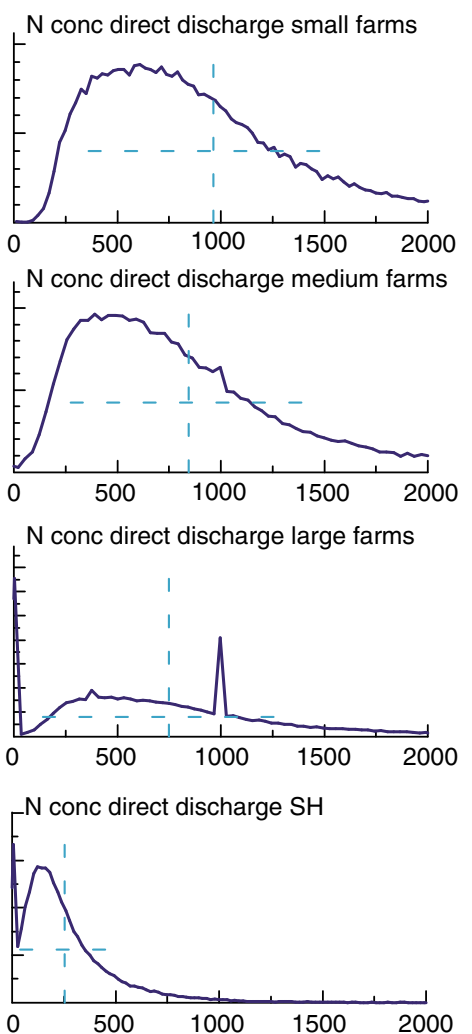

Fig. 5 Probability distribution for the Monte Carlo simulation for nitrogen concentrations (conc) in the discharge flows to TR ( $\mathrm{g} \mathrm{N} / \mathrm{kg}$ ); the area under the curve is equal to 1 (for reasons of readability, the units of the $Y$-axis are not shown; these units are not of interest, only the shape of the curve is important)

Table 7 Simulation results for the status quo of nitrogen flows from pig farming systems on the provincial level

\begin{tabular}{|c|c|c|c|c|c|c|c|c|c|c|}
\hline \multirow{2}{*}{$\begin{array}{l}\text { Province } \\
\text { Area }^{\mathrm{a}}\left(\mathrm{km}^{2}\right)\end{array}$} & \multirow[t]{2}{*}{ Indicator } & \multicolumn{2}{|c|}{ Small farms } & \multicolumn{2}{|c|}{ Medium farms } & \multicolumn{2}{|c|}{ Large farms } & \multicolumn{2}{|c|}{ Slaughter-house } & \multirow{2}{*}{$\begin{array}{l}\text { Total } \\
\text { province } \\
\mathrm{N} \text { (t/year) }\end{array}$} \\
\hline & & N (t/year) & $\begin{array}{l}\% \text { Of } \\
\text { province }\end{array}$ & $\mathrm{N}$ (t/year) & $\begin{array}{l}\% \text { Of } \\
\text { province }\end{array}$ & N (t/year) & $\begin{array}{l}\% \text { Of } \\
\text { province }\end{array}$ & $\mathrm{N}$ (t/year) & $\begin{array}{l}\% \text { Of } \\
\text { province }\end{array}$ & \\
\hline Chainat & & 150 & 67 & 40 & 18 & 30 & 13 & 5 & 2 & 220 \\
\hline \multirow[t]{2}{*}{2,500} & $\%$ Of basin & 11 & & 8 & & 2 & & 5 & & 7 \\
\hline & Places $^{\mathrm{b}}$ & 20,000 & & 9,000 & & 10,000 & & 58,500 & & 39,000 \\
\hline Suphanburi & & 590 & 79 & 80 & 11 & 60 & 8 & 20 & 3 & 750 \\
\hline \multirow[t]{2}{*}{5,400} & $\%$ Of basin & 44 & & 16 & & 4 & & 19 & & 22 \\
\hline & Places $^{\mathrm{b}}$ & 80,000 & & 20,000 & & 20,000 & & 180,000 & & 120,000 \\
\hline Nakhon Pathom & & 590 & 25 & 380 & 16 & 1,330 & 56 & 80 & 3 & 2,400 \\
\hline \multirow[t]{2}{*}{2,200} & $\%$ Of basin & 44 & & 76 & & 94 & & 76 & & 71 \\
\hline & Places $^{\mathrm{b}}$ & 80,000 & & 91,000 & & 420,000 & & 886,500 & & 591,000 \\
\hline Overall basin & & 1,330 & 40 & 500 & 15 & 1,420 & 42 & 105 & 3 & 3,400 \\
\hline 10,000 & Places $^{\mathrm{b}}$ & 180,000 & & 120,000 & & 450,000 & & $1,130,000$ & & 750,000 \\
\hline
\end{tabular}

${ }^{a}$ REO5 (2004)

b Pig places; for SH: Slaughtered pigs per year

\section{Data on pig farming and wastewater treatment}

Our estimations for nitrogen in feed intake and excretion (Tables 2,3) correspond well to the global figures given in de Wit et al. (1997; in Steinfeld et al. 2006). In terms of the ratio of nitrogen excreted from the uptake as feed, our results are in the lower range given by Menzi (2005), and well within the range indicated in Van der Peet-Schwering et al. (1999), which is based on European studies of digestible N contents in pig diets and practical pig production data. 
Table 8 Comparison of modeled results with results of other studies (the notation "value \pm standard deviation" is used for the simulation results)

\begin{tabular}{|c|c|c|c|}
\hline Quantity (unit) & Our result & Other studies & References \\
\hline $\mathrm{N}$ feed intake (g N/pig day) & $50 \pm 23$ & 53 & Witt et al. (1997) in: Steinfeld et al. (2006) \\
\hline $\mathrm{N}$ excretion (g N/pig day) & $38 \pm 15$ & 37 & Witt et al. (1997) in: Steinfeld et al. (2006) \\
\hline $\mathrm{N}$ ratio excreta/feed uptake $(\%)$ & $76 \pm 30$ & $\begin{array}{l}70 \\
70-90\end{array}$ & $\begin{array}{l}\text { Witt et al. (1997) in: Steinfeld et al. (2006); } \\
\text { Menzi (2005); Van der Peet-Schwering et al. (1999) }\end{array}$ \\
\hline \multicolumn{4}{|l|}{$\mathrm{N}$ in raw pig slurry $(\mathrm{mg} \mathrm{N} / \mathrm{l})$} \\
\hline Small farms & $850 \pm 620$ & $\begin{array}{l}3,800[2,700,4,870] \\
1,800-3,420\end{array}$ & $\begin{array}{l}\text { Scotford et al. (1998) } \\
\text { Moral et al. (2005) }\end{array}$ \\
\hline Medium farms & $740 \pm 590$ & & \\
\hline Large farms & $720 \pm 560$ & & \\
\hline \multicolumn{4}{|l|}{$\mathrm{N}$ concentration $\mathrm{AD}$ effluent (mg N/l) } \\
\hline Small farms & $610 \pm 380$ & $924-1,170$ & Cheng et al. (2004) \\
\hline Medium farms & $580 \pm 380$ & & \\
\hline Large farms & $520 \pm 350$ & & \\
\hline $\mathrm{N}$ removal efficiency $\mathrm{AD}(\%)$ & $50 \pm 10$ & 66 & Cheng et al. (2004) \\
\hline $\begin{array}{l}\mathrm{N} \text { concentration in raw } \mathrm{SH} \\
\text { wastewater }(\mathrm{mg} \mathrm{N} / \mathrm{l})\end{array}$ & $210 \pm 150$ & $\begin{array}{l}90-600 \\
1,300\end{array}$ & $\begin{array}{l}\text { Mittal (2006) } \\
\text { Murto et al. (2004) }\end{array}$ \\
\hline \multicolumn{4}{|l|}{$\begin{array}{l}\mathrm{N} \text { concentration in treated } \mathrm{SH} \\
\text { wastewater }(\mathrm{mg} \mathrm{N} / \mathrm{l})\end{array}$} \\
\hline $\mathrm{AD}$ & $150 \pm 120$ & $60-300$ & Mittal (2006) \\
\hline Pond & $210 \pm 180$ & & \\
\hline $\mathrm{N}$ removal efficiency SH AD (\%) & $50 \pm 10$ & $35-75$ & Mittal (2006) \\
\hline \multicolumn{4}{|l|}{ Specific N load per pig (g N/pig day) } \\
\hline Small farms & $20 \pm 15$ & $13.3[7.4,17.6]$ & Simachaya (1999) \\
\hline Medium farms & $11.3 \pm 8$ & & \\
\hline Large farms & $8.7 \pm 6.3$ & & \\
\hline \multicolumn{4}{|l|}{$\mathrm{N}$ load to Nakhon Pathom province } \\
\hline $\begin{array}{l}\text { Specific N load to Nakhon Pathom } \\
\text { province }\left(\mathrm{kg} \mathrm{N} / \mathrm{km}^{2} \text { year }\right)\end{array}$ & $1,100 \pm 500$ & $2,500-14,000$ & Badayos and Dorado (2004) \\
\hline Total pig farms (t N/year) & $2,400 \pm 940$ & & \\
\hline $65 \%$ of pig farms (t N/year) & $1,560 \pm 910$ & & \\
\hline $\mathrm{N}$ load to Chedi Bucha Canal (t N/year) & & $3,200 \pm 1,600$ & Bieri (2005); Walcher (2007) \\
\hline
\end{tabular}

The available scientific literature on piggery waste production reveals a wide range of slurry and effluent concentrations and loads, as a function of the climate, the waste retention and dilution as well as the treatment system types studied. Our average $\mathrm{N}$ concentrations in slurry and dung are only $25 \%$ of the $\mathrm{N}$ concentrations measured in the raw pig slurries of various European countries (Scotford et al. 1998). Compared to the concentrations reported for slurry samples analyzed from storage tanks in 36 commercial pig farms at different pig production stages by Moral et al. (2005), our values are roughly half as high.

In terms of treatment efficiencies, we compare our simulation results with Cheng et al. (2004) who studied the treatment efficiencies of $\mathrm{AD}$ and covered lagoons receiving wastewater from sows. Our AD effluent $\mathrm{N}$ concentrations (Table 6) are only roughly half as high. This discrepancy could be partly explained by the higher-strength raw wastewater originating from sow production, possibly in conjunction with lower system water use, as compared to our average mixed production farms.

As regards slaughterhouses, the wastewater concentrations of our model (Table 6) are in the lower section of the ranges indicated in a literature review of slaughterhouse wastewater treatment (Mittal 2006), but five times lower than the concentrations indicated in Murto et al. (2004). Considering our assumed high recovery rate of slaughtered pigs $\left(k_{\text {pork }}\right)$, lower concentrations of wastewater seem plausible. Our simulated treatment efficiencies for AD systems in $\mathrm{SH}$ are within the range of the studies on waste treatment systems reviewed by Mittal (2006) and correspond well with "low-rate" systems such as anaerobic (covered) lagoons. 
Field studies on nutrient discharge from pig farms in Thailand confirm our results for specific loads. Simachaya (1999) found an average total nitrogen load in the same range as our estimated specific nitrogen loads for the three farm types. A rough nutrient load estimation for pig production in Thailand (Badayos and Dorado 2004) classifies the area of Nakhon Pathom province under the highest nitrogen load-receiving category. Our simulated $\mathrm{N}$ loads (Table 7) are significantly lower than those estimates.

In order to conclude, the cross-check of our model results for pig waste production and treatment shows that generally our figures are lower than those of other studies. This is explained and justified by the fact that our results are conservative estimates and averages over the whole year, and not actual or peak emissions. In contrast, the experimental results of other authors are mainly based on point measurements.

\section{Data on surface water quality}

The Chedi Bucha Canal is an important and heavily polluted canal in Nakhon Pathom province, discharging from an area of highly concentrated pig farming. According to the statistics (DLD and PCD 2002), 65\% of the pig farming in Nakhon Pathom is concentrated in this area. Estimations of $\mathrm{N}$ loads in this canal on the basis of the water quality data of Bieri (2005) and the discharge measurements of Walcher (2007) amount to a daily load of roughly $8.8 \mathrm{t} \mathrm{N}$ or an annual nutrient load of 3,200 $\mathrm{t} \mathrm{N}$ from this canal (Table 8). These load estimations must be considered very carefully, assuming an uncertainty of not less than 50-100\%: the extrapolations are based on water quality point measurements made in 2004 and point discharge estimations made in 2006.

The difference between simulated and estimated loads may be due to the following three reasons: (1) Domestic areas (provincial capital and rural settlements) and crop agriculture (mainly rice and sugar cane) also contribute considerably to the nitrogen discharge in the catchment area; (2) Sedimentation is responsible for a certain "loss" of $\mathrm{N}$ from the water body, and thus not all the discharged nutrients can be measured in the surface water; (3) Potential denitrification in surface waters due to high temperatures and slow-moving water. Based on Reinhardt et al. (2006), Müller (pers. comm.) estimates a denitrification-N loss from slow-flowing surface waters in warm climates of up to $30 \%$.

The first reason would increase whereas the second and third ones would decrease the simulated loads.

Sensitivity analysis and scenario discussion

The sensitive parameters of the nitrogen loads to TR are determined and evaluated with regard to possible measures to reduce the environmental impact. The procedure for deriving possible measures is as follows (see also Kwonpongsagoon et al. 2007):

(1) Determine which parameters are sensitive to the key variable of interest

(2) For the sensitive parameters simulate the highest possible reduction (reduction potential)

(3) Determine the realistic reduction potential on the basis of the current system knowledge

(4) Discuss and compare the various possible measures.

Scenario discussion: realistic reduction potential of $N$ load to Thachin River Basin

We present three possible scenarios which target different aspects of potential nutrient mitigation related to the sensitive parameters identified. The scenarios are applied to all the farm types. Note that our selection of possible scenarios is not complete. Although other scenarios may also produce significant effects, we selected those that we consider to have the greatest potential [for a detailed analysis of steps 1 and 2 above see Schaffner (2007)]. Table 9 summarizes the three scenarios, showing the altered parameters and the respective $\mathrm{N}$ load reduction potential for the individual farm types and the total pig system (including $\mathrm{SH}$ ) compared with the status quo conditions.

Scenario 1: Increase treatment efficiency

Liquid waste management systems (POND and AD) of all the farms, with present treatment coverage: $k_{\text {emis_pond; }}^{(N)}$; $k_{\text {settle }}^{(N)} ; k_{\text {leach_pond }} ; k_{\text {emis_AD }}^{(N)}$, and $\mathrm{k}_{\text {biomass }}^{(N)}$

In the first scenario, we investigate the potential of reducing $\mathrm{N}$ loads by increasing the treatment efficiency of liquid waste management systems (POND and AD). For the corresponding POND parameters, we adopt the maximum rates indicated by DLD experts, assuming these reflect the upper level of realistic treatment efficiency achievable in local (TRB) conditions. A reduced leaching rate is considered an implicit aspect of technological improvement of the system. For AD systems, the treatment efficiency of our status quo model already exceeds the DLD expert indications. Therefore, to simulate the optimum N-treatment efficiency, we adopt the maximum of $70 \%$ given in Yang and Gan (1998) and accordingly increase the $\mathrm{N}$ emissions to $30 \%$ and the biomass $\mathrm{N}$ to $40 \%$.

The simulations with the altered parameters indicate a potential $\mathrm{N}$ load reduction of $20 \%$ for the total pig system in the Thachin Basin. The effect is the greatest for large farms $(34 \%)$, lowest for small farms $(6 \%)$, and average for medium farms. This discrepancy is due to the different degrees of treatment coverage: only farms with treatment systems can benefit by improving their efficiency. The 


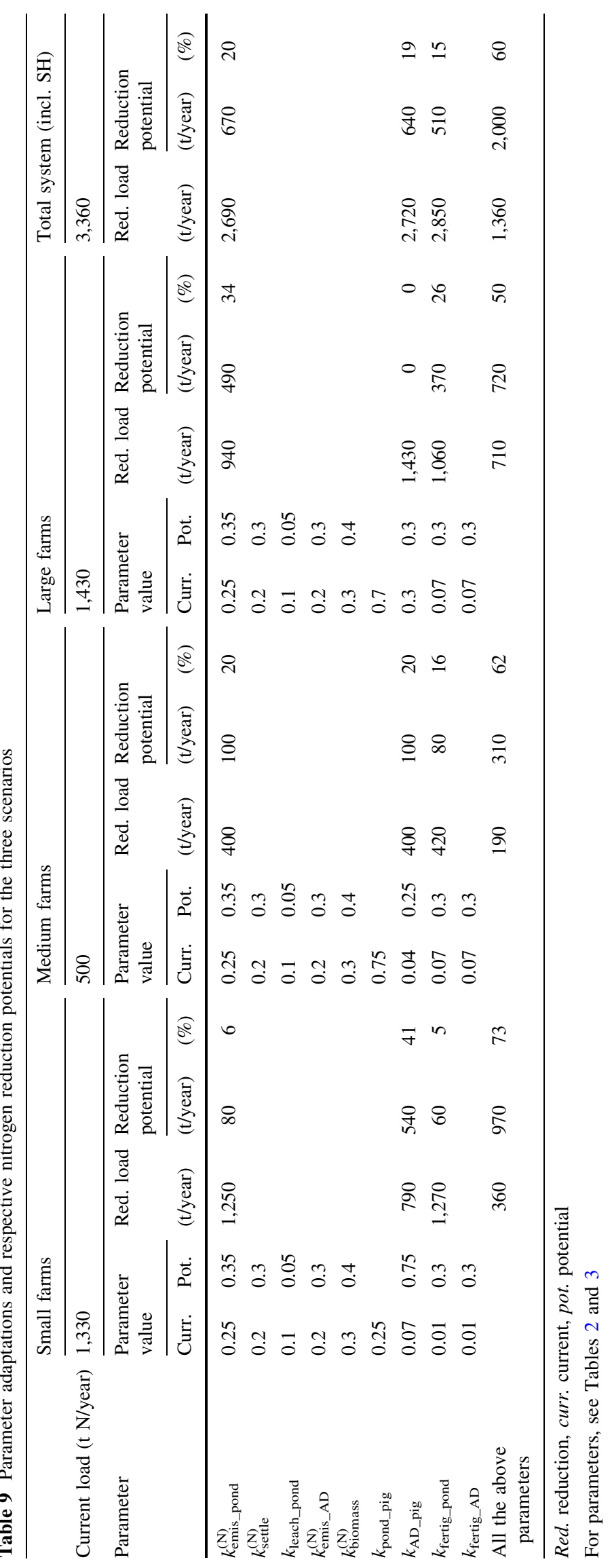


treatment coverage is consequently addressed as the second aspect in Scenario 2.

Scenario 2: Increase treatment coverage

All farms, with present treatment efficiency: $k_{A D_{-} \text {pig }}$

Many of the pig farms in the Thachin Basin, small farms, in particular, still lack treatment systems and discharge their raw waste directly to water bodies. Therefore, for Scenario 2, we increase the treatment coverage to an optimum of $100 \%$ for all the farm types. However, it is unrealistic to introduce any more POND systems in addition to the current ones due to a lack of sufficient extra land in the areas of intensive pig production (POND systems require considerable space). New treatment systems are therefore introduced in the form of $\mathrm{AD}$, and we increase the $\mathrm{AD}$ coverage parameter $\left(k_{\mathrm{AD} \_ \text {pig }}\right)$ so that $k_{\text {AD_pig }}+k_{\text {Pond_pig }}=1$.

This scenario results in a potential total $\mathrm{N}$ load reduction equivalent to Scenario 1 (20\%). In terms of individual farm contributions, however, the effects are opposite: $\mathrm{N}$ load reduction with Scenario 2 is the highest for small farms (over 40\%) and average for medium farms (20\%), while large farms remain at the status quo level ( $0 \%$ reduction).

Scenario 3: Increase liquid manure reuse

All farms, with present treatment coverage and efficiency: $k_{\text {fertig_pond }}, k_{\text {fertig_AD }}$

This scenario reflects the principle of closing the nutrient loop. We increase the rate of liquid manure reuse from POND and AD systems to crop agriculture and aquaculture ( $k_{\text {fertig_pond }}$ and $\left.k_{\text {fertig_AD }}\right)$. According to Gerber and Steinfeld (2006), a high reuse rate of liquid waste would be desirable but is difficult to implement with the current spatial distribution of livestock and crop production activities in the central plains of Thailand. Owing to the considerable distance between pig production sites and agricultural cropland, transferring liquid waste to crops requires costly transportation. Reusing liquid manure is more realistic in rural areas, where sufficient agricultural cropland is available to accommodate the nutrients from liquid manure. In the Thachin Basin, such rural areas exist to the north (in Chainat and Suphanburi provinces), which generate roughly $20 \%$ of the total pig production of the basin (see Table 7), and in the northern areas of Nakhon Pathom province. Assuming all of the liquid manure produced could be reused in these rural areas, we increase the recycling rate of $\mathrm{POND}$ and $\mathrm{AD}$ end-products to $30 \%$, according to this spatial distribution of pig production in the basin.

The scenario calculations show a basin-wide potential $\mathrm{N}$ load reduction of $15 \%$, somewhat lower than for Scenarios 1 and 2. The largest reduction potential is achieved in large farms $(25 \%)$, while the smallest farms show the least response $(5 \%)$. This scenario is again related to the ratio of farms connected to treatment systems, as the reuse rate applies only for treated liquid waste, and not for direct discharge.

\section{Scenario comparison}

From an overall system perspective, all the three scenarios show a considerable $\mathrm{N}$ load reduction potential of $15-20 \%$. However, depending on the farm type, the $\mathrm{N}$ load reduction effects of the studied scenarios vary greatly (Table 9). As regards the viability of implementation, the three scenarios require different basic conditions.

Treatment efficiency: For Scenario 1, existing treatment schemes are upgraded. From a technological perspective, this would be feasible considering that the improved efficiency is in line with the maximum value indicated by local experts. Menzi (2005) however, questions such an attempt, noting that treatment can hardly solve a nutrient surplus problem, at least not at a reasonable cost. A valuable alternative would be to reuse this effluent as a nutrient resource in crop agriculture (see Scenario 3), especially in areas where the irrigation water supply is limited (Rattanarajcharkul et al. 2000). Also, increasing the rate of dung separation would reduce liquid manure concentrations. However, the current trend in the Thachin Basin is rather the opposite: Somchai (pers. comm.) has observed a steady increase of $\mathrm{AD}$ systems which do not require dung separation, as the whole pig waste is collected and treated as slurry.

Treatment coverage: The Thai government is well aware of the problem of the direct discharge of raw pig waste. Discussions of how to include this farm category within the regulations are under way. The limited land area is often cited as a key obstacle in the attempt to increase treatment coverage (Gerber 2006), especially if the farms are located within a gradually urbanizing area such as the Thachin Basin. Scenario 2 addresses this constraint by promoting AD systems which enable high potential treatment efficiency on little space. Nevertheless, to achieve $100 \%$ treatment coverage in the basin is a very optimistic aim. Significant promotion activities and economic incentives would certainly be needed to induce all the farmers in the area to establish AD treatment systems with their associated costs. The small-scale household enterprises in particular may lack the economic basis for such an investment, a fact which may explain the low treatment coverage in this farm category. However, if AD systems include biogas production, the electricity produced could be used to meet on-farm energy requirements and thus produce a return on investment costs. A combination with Scenario 3 (increased liquid manure reuse) may also generate economic benefits in the long term (where sufficient crop land is available).

Liquid manure reuse: The lack of liquid manure reuse has been well identified by the AWI project as "the main 
environmental threat of intensive livestock production" (DLD and FAO 2004). However, the economic benefit of reusing liquid waste is low, except for farms with sufficient adjacent agricultural land. Owing to the high dilution of the slurry by cleaning and cooling water, transport volumes and corresponding costs are high, and fertilizing quality is low. Simply upgrading logistics and coordinative arrangements between livestock and crop farming activities will not be sufficient to compensate for such drawbacks. Thus, the extent to which the liquid manure reuse rate can be increased is dependent on the crop land available in the vicinity of the pig production units. In order to achieve a $100 \%$ reuse rate of all of the liquid manure produced in the Thachin Basin would imply relocating farms from urbanized, confined spaces to rural areas (Gerber and Steinfeld 2006). This is not considered practicable in the short and medium terms.

In order to conclude, from the point of view of nitrogen load reduction, all the scenarios have a significant effect of over 15-20\% (liquid manure reuse, treatment efficiency and coverage). In contrast, the effluent $\mathrm{N}$ concentrations are still high above the required standards. However, the crucial target to improve the quality of the receiving waters at a regional level is the reduction of the nutrient load; while the quality of the effluents remains a local-level issue.

\section{Conclusions}

This study shows that with an MFA model based on profound system knowledge, it is possible to gain an overview of the dimensions of the various pollution flows from pig farms to surface waters, to identify the key flows, and to discuss possible and effective remediation scenarios. For such a first-hand overview, the above-presented model is accurate enough. The comparison of our results with other studies shows that our figures are conservative in the sense that the total $\mathrm{N}$ load to the Thachin River could even be higher. The MMFA model aims at quantifying the orders of magnitude of pollution flows, to determine the key priorities for mitigation. Thus our model is complementary to other more detailed studies, such as process-based models, which can consequently be carried out to specifically investigate those priority flows identified.

Within the pig production system of the TRB, liquid waste discharge produces the bulk of surface water nitrogen pollution. This occurs as direct discharge of raw pig waste, mainly from small farms, and as overflow/effluent from large-farm liquid treatment systems. Medium farms contribute little to the nitrogen load, and the input from slaughterhouses is negligible. Potential measures to effectively reduce these flows are: (1) to increase the treatment efficiency for all the farm types, (2) to increase the treatment coverage for small and medium farm types or (3) to increase the reuse of liquid manure for all the farm types. The simulations show that each of these measures would have an approximate $20 \%$ reduction potential for the net nitrogen load to the basin.

Finally, a more balanced pig diet may reduce nitrogen excretion by as much as $30-39 \%$ depending on the initial diet composition (Steinfeld et al. 2006). This would directly lower the nitrogen excretion of pigs (at the source), with a linear effect on the resulting nitrogen load to the TRB.

Acknowledgments The research for this article was carried out within Work Package 3 of the Swiss National Centre of Competence in Research (NCCR) North-South: Research Partnerships for Mitigating Syndromes of Global Change. The project is co-funded by the Swiss National Science Foundation (SNF), and the Swiss Agency for Development and Cooperation (SDC), and part of a partnership between the Asian Institute of Technology (AIT), the Swiss Federal Institute of Aquatic Science and Technology (EAWAG), and the Hydrology Group of the University of Berne. The authors would like to express their sincere gratitude to the following local and international experts for generously sharing their knowledge and experiences on the pig farming system in Thailand: Dr. Arux Chaiyakul, Dr. Adisorn Chanprapalert, Dr. Somchai Chantsavang, Dr. Sommai Chatsanguthai, Dr. Pierre Gerber, Dr. Roongnapa Korparditskul, Dr. Dirk Lamberts, Dr. Harald Menzi, Dr. Sumet Mettasart, Dr. Beat Müller, and Dr. Kattaporn Poopej.

\section{References}

Baccini P, Bader H-P (1996) Regionaler Stoffhaushalt. Erfassung, Bewertung und Steuerung. Spektrum Akademischer Verlag, Heidelberg

Baccini P, Brunner PH (1991) Metabolism of the anthroposphere. Springer, New York

Badayos R, Dorado M (2004) Environmental baseline study (EBS): nutrients migration to South China Sea. World Bank/GEF

Bader H-P, Scheidegger R, Real M (2006) Global renewable energies: a dynamic study of implementation time, greenhouse gas emissions and financial needs. Clean Technol Environ Policy $8(3): 159-173$

Bieri F (2005) Water quality assessment and analysis in Thachin River Basin, Thailand. Masters Thesis, University of Bern

Binder C, Schertenleib R, Diaz J, Bader H-P, Baccini P (1997) Regional water balance as a tool for water management in developing countries. Int J Water Resour Dev 13(1):5-20

Brunner PH, Daxbeck H, Henseler G, von Steiger B, Beer B, Piepke G (1990) RESUB - der Regionale Stoffhaushalt im Unteren Bünztal: die Entwicklung einer Methodik zur Erfassung des regionalen Stoffhaushaltes. EAWAG, Dübendorf

Cheng J, Shearin TE, Peet MM, Willits DH (2004) Utilization of treated swine wastewater for greenhouse tomato production. Water Sci Technol 50(2):77-82

DLD (2004) Effect of piggery farms to Thachin River (in Thai). Department of Livestock Development, Bangkok

DLD, FAO (2004) Area wide integration (AWI) of specialised crop and livestock activities. Department of Livestock Development, Ministry of Agriculture and Cooperatives, Bangkok

DLD, PCD (2002) Plan and procedure for pig farm wastewater management in Thachin and Maeklong River Basins (in Thai). 
Department of Livestock Development and Pollution Control Department, Bangkok

FAO, DLD (2002) Policy implications of area-wide integration (AWI) of specialized crop and livestock activities: identification of technology and policy options in Eastern Thailand. Food and Agriculture Organization of the United Nations and Department of Livestock Development/Ministry of Agriculture and Cooperatives, Bangkok

Gerber P (2006) Putting pigs in their place, environmental policies for intensive livestock production in rapidly growing economies, with reference to pig farming in Central Thailand. $\mathrm{PhD}$ Thesis, Swiss Federal Institute of Technology, Zurich

Gerber P, Steinfeld H (2006) Regional planning or pollution control? Policy options addressing livestock waste, with reference to industrial pig production in Thailand. In: Gerber P (2006) Putting pigs in their place, environmental policies for intensive livestock production in rapidly growing economies, with reference to pig farming in Central Thailand. PhD Thesis, Swiss Federal Institute of Technology, Zurich

Gerber P, Chilonda P, Franceschini G, Menzi H (2004) Geographical determinants and environmental implications of livestock production intensification in Asia. Bioresour Technol 96(6):263276

Huang D-B, Bader H-P, Scheidegger R, Schertenleib R, Gujer W (2007) Confronting limitations: new solutions required in urban water management of a Chinese mega-city. J Environ Manage 84(1):49-61

Jönsson H, Vinneras B (2003) Adapting the nutrient content of urine and faeces in different countries using FAO and Swedish data. In: Proceedings from the 2nd international symposium on ecological sanitation, Luebeck, Germany

Kasetsart University, IRD (1996) Agricultural and irrigation patterns in the Central Plain of Thailand: preliminary analysis and prospects for agricultural development. Kasetsart University, DORAS Centre, Bangkok

Kwanmeung S (2002) Geographic information system for assessing land and subsurface water sensitivity to nitrate and phosphate contamination from swine farms in Muang District, Nakhon Pathom Province. Masters Thesis, Mahidol University, Bangkok

Kwonpongsagoon S, Bader H-P, Scheidegger R (2007) Modelling cadmium flows in Australia on the basis of a Substance Flow Analysis. Clean Technol Environ Policy 9(4):313-323

Lampert C, Brunner PH (1999) Materials accounting as a policy tool for nutrient management in the Danube basin. Water Sci Technol 40(10):43-49

LDD (1989) Soil map scale 1:50’000. Department of Land Development, Bangkok

Menzi H (2005) Need and implications of good manure and nutrient management in extensive livestock production in developing countries. In: Livestock waste management in East Asia project preparation Report. FAO, Rome

Menzi H, Ruettimann L, Gerber P (2002) NuFlux-AWI: a calculation model to quantify nutrient fluxes and balances of intensive livestock production in developing countries. In: Proceedings from the 10th international conference of the RAMIRAN network, High Tatras, Slovak Republic

Mittal GS (2006) Treatment of wastewater from abattoirs before land application-a review. Bioresour Technol 97(9):1119-1135

Moral R, Perez-Murcia MD, Perez-Espinosa A, Moreno-Caselles J, Paredes C (2005) Estimation of nutrient values of pig slurries in Southeast Spain using easily determined properties. Waste Manage 25(7):719-725

MOSTE (1996) Notification of the Ministry of Science, Technology and Environment, No. 3, 4 (1996), issued under the Enhancement and Conservation of National Environmental Quality Act (1992), published in the Royal Government Gazette, vol 113,
Part 13 D, dated February 13, 1996. Ministry of Science, Technology and Environment, Bangkok

MOSTE (2001) Notification of the Ministry of Science, Technology and Environment, issued under the Enhancement and Conservation of National Environmental Quality Act (1992), published in the Royal Government Gazette, vol 118, Special Part 8, dated February 23, 2001. Ministry of Science, Technology and Environment, Bangkok

Murto M, Bjornsson L, Mattiasson B (2004) Impact of food industrial waste on anaerobic co-digestion of sewage sludge and pig manure. J Environ Manage 70(2):101-107

Office of Natural Resources and Environmental Policy and Planning (2002) Thailand State of the environment report 2002: executive summary. Ministry of Natural Resources and Environment, Bangkok

PCD (1995) GIS database for Thachin River Basin. Pollution Control Department of Thailand, Bangkok

PCD, Environmental Consultant (2004) Project to improve the water quality of industrial waste water in Thachin River Basin (in Thai). Pollution Control Department, Bangkok

PCD, Pro-En Technologies (2002) Assessment of water reservoir's capacity in coping with pollution generated from trivial activities in conservative area-executive summary. Pollution Control Department, Bangkok

PCD, Thailand Environment Foundation, Montgomery Watson Asia, Coastal Consultancy International Pty Ltd. (1997) Development of an action plan to improve water quality in the Central River Basin, Thailand. Ministry of Science, Technology and Environment, Bangkok

Pfister F, Bader H-P, Scheidegger R, Baccini P (2005) Dynamic modelling of resource management for farming systems. Agric Syst 86(1):1-28

Portejoie S, Gerber P, Steinfeld H, Junelamate W, Liang JB, Salazar F, Salazar GG (2003) Manure management decision support tool. Process, design, references. AWI, Bangkok

Rattanarajcharkul R, Rucha W, Sommer S, Menzi H (2000) Areawide integration of specialised livestock and crop production in Eastern Thailand. In: Proceedings from the conference of the FAO/ESCORENA network on recycling agricultural, municipal and industrial residues in agriculture (RAMIRAN), Gargnano, Italy

Reinhardt M, Müller B, Gächter R, Wehrli B (2006) Nitrogen removal in a small constructed wetland: an isotope mass balance approach. Environ Sci Technol 40:3313-3319

Sarikaya HZ, Sevimli MF, Citil E (1999) Region-wide assessment of the land-based sources of pollution of the black sea. Water Sci Technol 39(8):193-200

Schaffner M (2007) Applying a material flow analysis model to assess river water pollution and mitigation potentials - a case study in the Thachin River Basin, Central Thailand. PhD Thesis, University of Bern. http://www.north-south.unibe.ch/content. php/publication/id/2093

Schaffner M, Koottatep T, Bader H-P, Montangero A, Scheidegger R, Schertenleib R (2005) Assessment of water quality problems and mitigation potentials by using material flow analysis-a casestudy in the Tha Chin River Basin, Thailand. In: Proceedings from the international symposium on the role of water sciences in transboundary river basin management, Ubon Ratchathani, Thailand

Schaffner M, Bader H-P, Scheidegger R (2009) Modeling the contribution of point sources and non-point sources to Thachin River water pollution. Sci Total Environ 407(2009):4902-4915

Scotford IM, Cumby TR, White RP, Carton OT, Lorenz F, Hatterman U, Provolo G (1998) Estimation of the nutrient value of agricultural slurries by measurement of physical and chemical properties. J Agric Eng Res 71(3):291-305 
Simachaya W (1999) Integrated approaches to water quality management using geographical information systems and the WASP5 simulation model: application to the Thachin River Basin, Thailand. PhD Thesis, University of Guelph

Simachaya W (2003) Lessons learned on integrated watershed and water quality management in the Thachin River Basin, Thailand. In: Proceedings from the first Southeast Asia water forum, Chiang Mai, Thailand

Sinsupan T (2004) Material flux analysis (MFA) for Planning of domestic wastes and wastewater management: case study in Pakkret Municipality, Nonthaburi, Thailand. Masters Thesis, Asian Institute of Technology, Bangkok

Somlyódy L, Brunner PH, Kroiss H (1999) Nutrient balances for danube countries: a strategic analysis. Water Sci Technol 40(10):9-16
Steinfeld H, Gerber P, Wassenaar T, Castel V, Rosales M, de Haan C (2006) Livestock's long shadow-environmental issues and constraints. FAO, Rome

Thailand Meteorological Department (2001) Meteorological data for Suphanburi Station (1971-2000). Thailand Meteorological Department, Bangkok

Van der Peet-Schwering CMC, Jongbloed AW, Aarnink AJA (1999) Nitrogen and phosphorus consumption, utilisation and losses in pig production: The Netherlands. Livest Prod Sci 58(3):213-224

Walcher C (2007) Hydrological patterns in the Thachin River Basin, Thailand. Masters Thesis, University of Bern

Yang PY, Gan C (1998) An on-farm swine waste management system in Hawaii. Bioresour Technol 65(1-2):21-27

Zessner M, Kroiss H (1999) Retention and losses of nutrients in the hydrosphere of Austria. Water Sci Technol 40(10):59-66 